http://les1.man.ac.uk/prest

》)

\section{Foresight Concepts in the European Commission}

\author{
by Werner Wobbe, European Commission ${ }^{1}$, \\ DG Research, Brussels, Belgium
}

Foresight activities have been run by the Services of the European Commission in different programmes and locations for more than twenty years. The Research Directorate-General (DG) has always carried out the most prominent part. Now a specific unit is dealing with foresight issues and it will establish a "Foresight KnowledgeSharing platform" that is to benefit the whole foresight community in its role either as producers of foresight knowledge or as users of that knowledge. In this way foresight contributes to new governance concepts suggested by the Commission. The European foresight activities are also geared to the European Research Area as well as to innovation.

\section{Introduction}

Foresight is understood in the European Commission as a tool for policy design and shaping. It has a strategic intelligence function for Community or European Union policies. Foresight contributes to orientations and priorities of EU policies. Usually, these contributions are introduced by research carried out by independent experts. Commission officials synthesise the results or reformulate recommendations that emerge from contract research.

Europe's specificity is its diversity and European level activities are mainly a blend of national policies, national cultures and traditions. European policies as well as European administrative behaviour have different national points of departure and origin and may be transformed or blended by other national ingredients. As often observed, the French administration initially had a strong influence on the Commission. The influential French tradition of prospectivists probably was a reason why foresight was accepted early in the Commission. Later, British consultants gained influence and as the UK Foresight Programme was launched in the mid-nineties it left its trace on the Commission activities. One of these traces was the 
term foresight that was used by a new unit set up in DG Research in $2001^{2}$.

\section{A Brief Foresight History in the Com- mission}

Commissioner Ralf Dahrendorf made what is probably the first attempt at foresight in the late 1970's. Dahrendorf's academic carrier was briefly interrupted when he took a German Government position that was followed by a brief position as a Commissioner of the European Communities. In this position he ordered an internal report called "Europe plus 30" (1978). He subsequently went to teach at the London School of Economics.

The report gave birth to a foresight programme in the Commission's research department, the FAST programme. FAST stands for "forecasting and assessment in science and technology" and was set up to deliver policy advice to the research DG. The programme was headed by Riccardo Petrella, a charismatic person, who ran the programme for 15 years from 1979 to 1994 , including two programme renewals. ${ }^{3}$ The mandate and the various projects FAST ran were mainly carried out in the spirit of a foresight programme instead of a science and technology assessment activity because it was to explore new avenues for research policies.

Technology assessment approaches were in demand from several parliamentary institutions in the Member States. Consequently, the European Parliament also came up with an initiative. Created in 1986, STOA - the Scientific and Technological Options Assessment programme at the European Parliament was initiated by Rolf Linkohr (MEP) in order to serve this purpose at the time.

Commission President Jacques Delors, who was also interested in intellectual reflections, brought the French tradition of "la prospective" into play and created a special service, the Cellule de Prospective. The Cellule was attached to the President's office and run a series of future-oriented reflections on policies that were of a general nature and not restricted to science and technology developments. President Prodi recently transformed the Cellule into a policy advisory group, giving up foresight activities.
When the FAST programme disappeared, it was succeeded by several activities at European level. The Institute for Prospective Technological Studies (IPTS) was established in Seville, Spain, in the mid-nineties as an institute of the Joint Research Centre of the European Communities. Its first head was the former director of the MONITOR programme, Herbert Allgeier. The IPTS got the mandate to inform the Commission on new science and technology developments by its own research ${ }^{4}$. The fourth Framework Programme for research and technological development took on board a new specific programme on "Targeted socioeconomic research" (TSER) that gave birth to a "European technology assessment network: ETAN" as a pilot action for policy related research. The policy research centred on science and technology and innovation issues was carried on in the fifth Research Framework Programme in research activities called STRATA. These activities involved analytical and synthesis work on a limited number of specific issues related to science and technology policies.

\section{New Policies for the New Millennium}

The heads of State and Government of the European Union at their March 2000 meeting in Lisbon, agreed on a common vision for economic and social development in Europe as a new policy approach. The vision aims at making the EU, by 2010, "the most competitive and dynamic knowledge-based economy in the world, capable of sustainable economic growth with more and better jobs and greater social cohesion". The objective of the so-called Lisbon strategy serves as a Benchmark for the EU. Europe is perceived as lagging behind its competitors in various research and innovation aspects so that research and innovation policy has been set to become one of the key instruments.

Two years later, the European Council launched in Barcelona a call for action to increase investment in research and close the gap with Europe's main competitors. Investment in research should rise from $1.9 \%$ to $3 \%$ of GDP in the European Union by 2010, and the share funded by business should rise to two-thirds of the total. Since then relevant stakeholders have agreed to act on the lines suggested by the Commission ${ }^{5}$. 
In 2000, the European Commission recommended as one of the key areas for action, the development of a European Research Area. The ERA has to identify excellence, to strengthen pan-European collaboration and to establish clearer and more consistent priorities for public research. This would also provide higher visibility to European excellence in science and research for researchers in other parts of the world. Until now a distributed potential and a high diversity of knowledge have not merged at the European level and European research often falls short of realising its true excellence.

The new multiannual Framework Programme for research, technological development and demonstration activities (FP6, 20022006) will be a key instrument of this strategy by fostering the concertation of Member States activities.

\section{A New Foresight Unit in the Research Directorate-General}

These political developments have led to the decision of the Research DG to create again a foresight unit in-house that is to contribute to strengthening the foundations of the European Research Area and to support a coherent development of research and innovation policies.

The development of a strong and integrated research and innovation area in Europe needs a vision on prospective growth areas. A strategy has to reflect the future. Forecasting, technology assessment, future studies and other forms of foresight try to identify long-term trends and thus to guide decision-making. Foresight, which has emerged mainly in Europe during recent years, aims at identifying today's research and innovation priorities on the basis of scenarios of future developments in science and technology (S\&T), society and economy. Therefore, foresight has a potential to improve research and innovation policies and to strengthen the strategic dimension of the European Research Area.

This unit sees foresight as a systematic, participatory, future intelligence gathering and medium-to-long-term vision-building process aimed at present-day decisions and mobilising joint actions. The term "Foresight" therefore represents the processes focusing on the interaction between science, technology and soci- ety. It is assumed that foresight has a potential to improve research, technology and innovation policies and that foresight is able to strengthen the strategic dimension of the European Area for Research and Innovation. Attributable policy effects may take the form of new or revised

- RTDI goals, instruments, and procedures of public and private programmes;

- Policy measures concerning both framework conditions for "innovation" (sciencesociety relations, industrial relations, human resources mobility, Intellectual Property Rights, etc.) and consequences for other policy fields (working and living conditions, equality of gender, social exclusion, etc.).

Other significant, but more indirect effects can be expected through the generation of a broader consensus, promotion of strategic-level thinking, focusing on the accumulation of policyrelevant knowledge, etc.

\section{Foresight as a Tool for New Governance Approaches}

The Commission has declared better governance one of its priorities. Governance is understood as rules, processes and behaviour that effect the way in which power is exercised in Europe. The White Paper on European Governance (European Commission 2001) intends to involve more people and organisations in policy making and pleads for more openness, accountability and responsibility. At the proposal of the European Commission, the Council and the European Parliament may adopt legislative and budgetary acts. The execution of policies is entrusted to the Commission and national authorities. Taking into account the diversity of national institutions the Commission favours economic policies based on framework directives and coregulation in order to assure a smother implementation of these policies.

If we talk about economic and social policies where innovation is of pivotal nature the Commission intends to lead the European policy agenda through its Communications and its accompanying action plans. The Member States tend to adopt these European policy agendas in national policies. Policy issues like the notion of competitiveness, its fostering or 
hindering factors, benchmarking, economic framework conditions, sustainability and best available technologies, the information society and knowledge society, evaluation and the reform of the higher education, etc were initiated by European debates. This policy approach geared to open debates leads not as much to directives and decisions of the Commission as to new forms of co-operation between Member States and the Commission.

In a policy science perspective, the policydecision making process is not a stand-alone act but a process (see Caracostas 2003). Key questions are who dominates the policy agenda and how interest groups are involved (see Muller 1994). In order to implement its policies, the Commission works on consensus building in the inner-institutional constellations but also in Committees with Member State representatives as well as in form of intergovernmental cooperation (see Telò 2003). A particular method of this co-operation scheme that does not use legislative power for policy implementation is the "open method of co-ordination", a specific form of co-operation between Member States and the Commission via various forms of benchmarking. ${ }^{6}$ The Commission issues recommendations and does monitoring while the Member States are required to report on progress and implement the guidelines at national level according to the given conditions. This open but informed method or process is essential for governance concepts integrating a broad range of stakeholders and experts in policy making. It has become a specificity of European politics as well as of governance. Foresight may contribute well to these methods of governance.

Europe is struggling to keep up the pace of innovation. This problem may not be resolved by classical legislative measures. Questions associated with the issue are:

- How to make knowledge production a central policy aim;

- How to deal with heterogeneity after Enlargement;

- How to make value added from distributed knowledge in Member States; or

- Will the new Treaty draw more attention to ERA, Higher Education and S\&T?

In any case, foresight procedures may contribute to tackling these open questions by bring- ing in a range of societal and economic stakeholders that are Europe's asset. We may conclude that Europe has taken a route to governance and to a structured "open method of co-ordination" that requests those national policies to develop shared-policy intelligence. Foresight contributes to this development because it aims at thinking, debating and shaping the future. Foresight has developed from technological visions encompassing the range from pure economic forecasting to stakeholder participation. In this way, it touches the dimension of soft power embodied in the governance concept.

\section{European Foresight Knowledge-Sharing Platform}

In Europe, a range of national foresight activities currently exists. The first comprehensive national programme was the UK Foresight programme. Its first round of Foresight took place between 1994 and 1999. It covered fifteen industrial sector expert panels. The second round of Foresight took place from 1999 to 2002 and had three thematic and ten sector panels. The third round started in April 2002 and it concentrates on four thematic areas. ${ }^{7}$ In France, a large exercise was held on "Key Technologies" for the Ministry of Industry. In 2003 a new and even more comprehensive activity started. It is called FUTURIS, and it is co-ordinated by ANRT (National Association for Technical Research) with the intention of leading a broad societal dialogue. In Germany, the Ministry of Education and Research runs a remarkable exercise, the FUTUR programme. This activity, based on new stakeholder participation, aims at developing new science and technology priorities. In addition to those mentioned, further programmes and activities exist in other Member States at sub-national level (see Renn, Thomas 2003).

Considering all the initiatives, activities and institutions in Europe and following a High Level Expert Group report ${ }^{8}$, the Commission services have decided not to add a new institution at European level but to create a platform for exchange, networking and collaboration. In order to support the exchange and European co-operation, the Commission Services will offer resources to the foresight community in 
Europe. The Commission will inform the foresight community by monitoring and mapping foresight activities at world level and making results available to European foresight actors. The Commission will contribute to transparency between European actors and foster a European dimension. The Commission (DG Research working closely with the IPTS) will also support methodological developments and mutual learning. Another genuine aim is to foster a European view of foresight that supports regional or national activities and may enlarge their perspectives.

The preparation for the KnowledgeSharing Platform is underway and it should be in full operation in 2004. Calls for tender for service activities to support the initiative have been announced in a prior information notice in April 2003. ${ }^{9}$

\section{Notes}

1) Disclaimer: "The views expressed are purely those of the writer and may not in any circumstances be regarded as stating an official position of the European Commission".

2) European Commission, Directorate General Research, unit "Science and Technology Foresight, links with the IPTS". The Head is P. Caracostas. See "Mission and activities of the 'Science \& Technology Foresight' unit", Brussels, March 2003, http://www.cordis.lu/rtd2002/ foresight/home.html.

3) The last phase was renewed as a subprogramme under the MONITOR programme.

4) For information on JRC/IPTS activities see: http://www.jrc.es/welcome.html.

5) $\operatorname{COM}(2002) 499,11$ Sept. 2002.

6) The European employment policy is the most prominent example.

7) Current projects are: Cognitive Systems, Flood and Coastal Defence, Cyber Trust and Crime Prevention and Exploiting the Electromagnetic Spectrum. See also the article by I. Miles and M. Keenan in this issue.

8) See also the article by Luk Van Langenhove in this issue.

9) This invitation to tender has been announced in a prior information notice for Services $\mathrm{n}^{\circ}$ 2003/S 70-060825 published in Supplement to the Official Journal of the European Union $n^{\circ}$ S70 on 9 April 2003.

\section{Literature}

Caracostas, P., 2003: Shared governance through mutual learning. In: Edler, J.; Kuhlmann, K. (eds.): Changing governance of research and technology policy. Cheltenham: Edward Elgar

European Commission, 2001: European Governance, A White Paper. COM(2001) 428 final, Brussels

Muller, P., 1994: La mutation des politiques publiques. $\mathrm{N}^{\circ}$ Spécial de la revue Pouvoirs sur l'Europe : De la Communauté à l'Union. Brussels

Renn, O.; Thomas, M., 2003: The potential of regional foresight. Final report of the STRATAETAN Expert Group "Mobilising the regional potential for an enlarged European Union - an essential contribution to strengthen the strategic basis of the European Research Area (ERA)". Brussels

Telo, M., 2003: Government and Governance in the European Union: The open method of coordination. In: Rodrigues, M.J. (ed.): The new knowledge economy in Europe. Cheltenham: Edward Elgar

\section{Contact}

Dr. Werner Wobbe

European Commission

Directorate-General for Research

Unit: Science and technology foresight, links with the IPTS

B-1049 Brussels, Belgium

Tel.: +32 - 2 - 2950879

E-mail:werner.wobbe@cec.eu.int 